\title{
USO DE SUBSTRATOS NA ESTAQUIA DE ASTRAPÉIA (Dombeya wallichii L.)
}

Michel Anderson Masiero ${ }^{*}$, Karina Gabrielle Resges Orives ${ }^{2}$, Lorena Clara Cruz ${ }^{3}$, Jean da Silva Amancio ${ }^{2}$, Maikely Luana Feliceti ${ }^{4}$, Carla Marins Santos Santana Viana ${ }^{1}$, Daniela Macedo de Lima ${ }^{5}$

\footnotetext{
${ }^{1}$ Discente do curso de Engenharia Florestal, Biotecnologia e Propagação Vegetal, Universidade Tecnológica Federal do Paraná - (UTFPR/DV), Dois Vizinhos, Paraná. *E-mail do autor correspondente: michel_masiero2@hotmail.com.

${ }^{2}$ Licenciada em Ciências Biológicas (UTFPR/DV), Dois Vizinhos, Paraná.

${ }^{3}$ Licenciada em Ciências Biológicas, Mestranda do Programa de Pós-Graduação em Biotecnologia da (UTFPR/DV), Microbiologia, Dois Vizinhos, Paraná.

${ }^{4}$ Licenciada em Ciências Biológicas, Doutoranda do Programa de Pós-Graduação em Agronomia (UTFPR/PB), Tecnologia de Semente, Pato Branco, Paraná.

${ }^{5}$ Docente nos cursos de Engenharia Florestal e Ciências Biológicas (UTFPR/DV), Dr $^{\mathrm{a}}$ em Agronomia (UFPR), Produção Vegetal, Dois Vizinhos, Paraná.
}

Recebido: 16/12/2018; Aceito: 20/08/2019

RESUMO: Dombeya wallichii, conhecida como astrapéia, é uma planta exótica originária do Madagascar, com características ornamentais e de grande importância para os apicultores, uma vez que sua inflorescência atrai muitas abelhas e seu florescimento se dá no outono e inverno, período crítico de alimento para as mesmas. O presente trabalho teve por objetivo avaliar o uso de substratos na propagação vegetativa de astrapéia por estaquia. A partir de brotações coletadas da base de uma planta matriz localizada no centro de Dois Vizinhos-PR, foram confeccionadas estacas de $10 \mathrm{~cm}$, sem folhas e com corte bisel nas extremidades. O delineamento experimental implantado foi o DIC (Delineamento Inteiramente Casualizado), com três tratamentos, sendo eles substrato orgânico comercial, terra e a mistura entre ambos os substratos na proporção $(1: 1)(\mathrm{V} / \mathrm{V})$, e quatro repetições de dez estacas por parcela. O plantio foi realizado em tubetes de polipropileno de $120 \mathrm{~cm}^{3}$, contendo os diferentes substratos, que foram acondicionados em bandejas mantidas na casa de sombra do Viveiro Florestal da Universidade Tecnológica Federal do Paraná - Campus Dois Vizinhos. Aos 74 dias, foram avaliadas as variáveis porcentagem de estacas enraizadas, com calos, mortas, vivas, com brotações, número e comprimento médio de raízes. Os dados foram submetidos à análise de variância $(\mathrm{P} \leq 0,05)$, utilizando o programa SISVAR 5.6. Para a propagação vegetativa de astrapéia são eficazes, o substrato orgânico comercial e a mistura substrato orgânico e terra caracterizaram-se como os melhores substratos.

Palavras-chave: Propagação vegetativa. Brotações. Estacas. Enraizamento.

\section{USE OF SUBSTRATES IN CUTTING OF ASTRAPÉIA (Dombeya wallichii L)}

ABSTRACT: Dombeya wallichii, known as astrapeia, is an exotic plant native to Madagascar with ornamental features and of great importance to beekeepers, since its inflorescence attracts many bees and their flowering gives in autumn and inverts, critical 
period of food for them. The present work had as objective to evaluate the use of substrates in the vegetative propagation of the astrapéia by cutting. From buds collected from the base of a matrix plant located in the center of Dois Vizinhos - PR, $10 \mathrm{~cm}$ cuttings were made, with no leaves and a bevel cut at the ends. The experimental design was DIC (Completely randomized design), with three treatments: commercial organic substratum, soil and the mixture between both substrates in the proportion $(1: 1)(\mathrm{V} / \mathrm{V})$, and four replicates of ten stakes per pair. planting was carried out in $120 \mathrm{~cm}^{3}$ polypropylene tubes containing the different substrates. They were stored in trays kept in the shade house of the Forest Nursery of the Universidade Tecnológica Federal do Paraná - Campus Dois Vizinhos. At 74 days, the percentage of rooted cuttings was evaluated, with calluses, dead, alive, with shoots, number and average length of roots. Data were submitted to analysis of variance $(\mathrm{P} \leq 0.05)$, using the SISVAR program 5.6. According to the results for vegetative propagation of astrapeia is effective, the commercial organic substrate and the organic substrate mixture and soil were characterized as the best substrates.

Key words: Vegetative propagation. Sprouts. Cuttings. Rooting.

\section{INTRODUÇÃO}

Dombeya wallichii, conhecida popularmente como astrapéia, é uma arvoreta de aproximadamente três a cinco metros, originária da África, mais precisamente da ilha de Madagascar, possuindo características ornamentais e paisagísticas (LORENZI et al., 2018). A espécie chama atenção pois possui folhas grandes, cordiformes, de cor verde brilhante, assim como suas inflorescências, de formato umbeliforme, sustentadas por longos pedúnculos, globosas e com numerosas flores de cor rosa a avermelhada, ricas em néctar e perfumadas (GONÇALVES et al., 2004; LORENZI et al., 2018).

Além de sua popularidade ornamental, a espécie tem grande importância para os apicultores, uma vez que suas inflorescências atraem muitas abelhas e sua floração se dá no outono e inverno, período crítico de alimento para as mesmas (ESPINDOLA; ORENHA, 2007; MASIERO et al., 2016). O estudo da espécie se torna importante, pois a mesma constitui-se como uma alternativa positiva para substituir e/ou complementar o uso de alimentação artificial no inverno, com o objetivo de aumentar a produtividade dos enxames (FIGUEIRÓ et al., 2010).

A propagação da astrapéia via sementes, apresenta alguns problemas indesejáveis como alta variabilidade genética e desuniformidade das mudas, procura-se então trabalhar com outras alternativas que sejam favoráveis para produção de mudas, como é o caso da propagação vegetativa (DIAS et al., 2012). Essa forma de propagação vem sendo muito utilizada pois, apresenta como critérios na produção de mudas, a uniformidade e viabilidade econômica.

Existem diferentes técnicas ou maneiras de se propagar uma planta, sendo a estaquia uma das principais (WENDLING et al., 2005; HARTMANN et al., 2018). Essa técnica de propagação vegetativa é embasada na totipotencialidade dos tecidos, onde os mesmos se regeneram pelo processo de divisão celular conhecido especificamente como mitose 
(HARTMANN et al., 2018). A estaquia é uma técnica rápida e fácil de ser executada, sendo muito utilizada em diversas espécies (BORGES et al., 2011).

A utilização de brotações para confecção de estacas permite uma maior juvenilidade das mesmas, facilitando a rapidez no enraizamento, devido apresentarem menos lignificação nos tecidos (WENDLING; DUTRA, 2010). Ressalta-se, também que a espécie se reproduz facilmente por estacas, com crescimento rápido emitindo inflorescências já no primeiro ano (ESPINDOLA; ORENHA, 2007).

Entretanto, para que haja uma boa propagação, também existem alguns fatores primordiais, entre eles uma boa condição da planta matriz e o tipo de substrato em que a planta será colocada para estaquia (AMARO et al., 2013). O substrato apresenta papel fundamental para o desenvolvimento das raízes nas estacas, devendo possuir baixa densidade, boa capacidade de absorção e retenção de água, boa aeração e drenagem para evitar o acúmulo de umidade, além de estar livre de pragas, doenças e substâncias tóxicas (KÄMPF, 2000; GOMES et al., 2015).

Alguns substratos vêm sendo muito utilizados na produção de mudas, como é o caso do substrato orgânico comercial. Esse substrato apresenta características físico-químicas favoráveis, como a presença de matéria orgânica, quantidade suficiente de cargas iônicas, porosidade e retenção de umidade satisfatória (ZIETEMANN; ROBERTO, 2007).

Existem diferentes marcas de substratos orgânicos comerciais presentes no mercado, sendo a que composição física de cada substrato pode ser diferente (KÄMPF, 2000). O substrato utilizado no presente trabalho é composto a partir de cascas de pinus bioestabilizadas, vermiculita, corretivo de acidez e macronutrientes. Outra alternativa de substrato orgânico muito utilizada na produção de mudas e de fácil acesso, é a utilização do composto orgânico oriundo de excrementos animais, sendo uma boa opção pelo baixo custo (GOMES et al., 2008).

Outro substrato que pode ser utilizado é a terra de barranco ou solo natural, que se apresenta como boa opção principalmente por apresentar como característica a viabilidade econômica (GAULAND, 1997). Sua utilização em misturas com outros compostos auxilia no desenvolvimento das mudas, visto que aumenta as características do substrato (densidade e nutrientes), além de ser uma prática rotineira dos viveiristas (GAULAND, 1997; PAULINO et al., 2011).

O presente trabalho teve por objetivo avaliar o uso de substratos na propagação vegetativa de astrapéia por estaquia.

\section{MATERIAL E MÉTODOS}

O estudo foi realizado no Viveiro Florestal da Universidade Tecnológica Federal do Paraná Câmpus Dois Vizinhos (UTFPR-DV), no município de Dois Vizinhos PR, (2544'03', $\mathrm{S}$ e $53^{\circ} 03^{\prime} 10^{\prime}$ ' W, $500 \mathrm{~m}$ de altitude) entre os meses de agosto a novembro de 2016 . Segundo a classificação de Köppen, o clima da região é temperado, do tipo Cfa, com temperatura do mês mais frio entre $3{ }^{\circ} \mathrm{C}$ a $18{ }^{\circ} \mathrm{C}$, sempre úmido, com chuva em todos os meses do ano e 
temperatura do mês mais quente superior a $22{ }^{\circ} \mathrm{C}$, mas no mínimo quatro meses com temperatura maior que $10{ }^{\circ} \mathrm{C}$ (ALVARES et al., 2013).

A planta matriz de astrapéia (Dombeya wallichii) está localizada no centro da cidade de Dois Vizinhos, PR. A partir da base da mesma coletou-se brotações e preparou-se estacas de $10 \mathrm{~cm}$ de comprimento, corte em bisel na base e ausência de folhas. Após preparadas, as estacas foram acondicionadas em tubetes de $120 \mathrm{~cm}^{3}$ contendo os diferentes substratos.

O delineamento experimental foi o inteiramente casualizado com três tratamentos e quatro repetições de dez estacas por parcela. Os tratamentos utilizados foram substrato orgânico comercial (SOC), terra de barranco (TB) e mistura de terra com substrato orgânico $(\mathrm{SOC}+\mathrm{TB})$. Para a mistura dos substratos utilizou-se a proporção 1:1 (V/V), para cada substrato. A escolha de terra de barranco como substrato se deu para facilitar e reduzir os custos da produção de mudas de astrapéia, uma vez que as informações obtidas nesse trabalho serão repassadas aos apicultores da região para que os mesmos consigam produzir suas próprias mudas em sua propriedade.

Os tubetes foram acomodados em bandejas mantidas na casa de sombra do Viveiro Florestal, onde permaneceram durante o período de 74 dias sendo irrigados duas vezes ao dia, pela manhã e ao final da tarde. Após esse período foram avaliadas as variáveis porcentagem de enraizamento $(\mathrm{E})$, sobrevivência $(\mathrm{S})$, calosidade $(\mathrm{C})$, mortalidade $(\mathrm{M})$, brotações $(\mathrm{B})$, número (NR) e comprimento médio de raízes por estaca (CMR).

Os dados foram submetidos à análise de variância e comparação de médias pelo teste Tukey. Ambos utilizando o nível de 5\% de probabilidade, usando como instrumento o auxílio do software SISVAR 5.6 (FERREIRA, 2011).

\section{RESULTADOS E DISCUSSÃO}

Os resultados obtidos com a utilização dos diferentes substratos foram favoráveis para o estudo, visto que os efeitos constatados nos dados, podem refletir e demonstrar o quanto a escolha do substrato adequado é importante para o sucesso do enraizamento das estacas, assim como identificar a eficiência do mesmo para propagação da espécie.

A análise apresentou graus de significância (1 e 5\%) para as variáveis, sendo significativa à $1 \%$, para à porcentagem de enraizamento $(\mathrm{E})$, mortalidade $(\mathrm{M})$ e porcentagem de brotações (B), e significativa a (5\%) para o número médio de raízes (NR) (Tabela 1). As demais variáveis não foram significativas (1 e 5\%). Dessa maneira o substrato demonstrou que foi um fator influente e significativo no trabalho. Esse resultado se confirma devido a principal variável, o enraizamento (E), uma vez que ela apresentou significância, ou seja, houve diferença entre os substratos. De tal modo o desenvolvimento inicial da emissão das raízes nas estacas foi afetado pelo substrato utilizado em questão.

$\mathrm{Na}$ comparação de médias os substratos demostraram diferença estatística à $5 \%$ para as variáveis: enraizamento (E), número médio de raízes (NR), mortalidade (M) e porcentagem de estacas com brotações (B), sendo que para as demais não foi verificada significância (Tabela 2 e Tabela 3). 
Tabela 1. Resumo da análise de variância contendo os valores do quadrado médio para as variáveis enraizamento $(\mathrm{E})$, número de raízes $(\mathrm{NR})$, comprimento médio das raízes (CMR), sobrevivência $(\mathrm{S})$, mortalidade $(\mathrm{M})$, porcentagem de calosidade (C) e porcentagem de brotações (B) em estacas de astrapéia (Dombeya wallichii) em função de diferentes substratos. Dois Vizinhos, PR, UTFPR, 2016. Abstract of the variance analysis with the value middle square to rooting variables $(E)$, roots numbers $(N R)$, mean root length $(C M R)$, survival $(S)$, mortility $(M)$, porcentage of callosity $(C)$ Sprout porcentage $(B)$ on stakes of astrapéia (Dombeya wallichii) in function of different substrates. Dois Vizinhos, PR, UTFPR, 2016.

\begin{tabular}{lcccccccc}
\hline \multicolumn{1}{c}{ FV } & GL & E & NR & CMR & S & M & C & B \\
\hline Fator (SB) & 2 & $1858,33^{* *}$ & $4,91^{*}$ & $3,72^{\text {ns }}$ & $8,33^{\text {ns }}$ & $2500,00^{* *}$ & $58,33^{\text {ns }}$ & $2508,33^{* *}$ \\
Resíduos & 9 & 130,55 & 0,895 & 3,853 & 75,00 & 122,22 & 16,66 & 208,35 \\
\hline Total & 11 & & & & & & & \\
\hline CV $(\%)$ & & 20,46 & 21,37 & 33,60 & 122,22 & 31,59 & 122,47 & 35,50
\end{tabular}

ns não significativa, a 5\% de probabilidade ** Significativo a $1 \%$ de probabilidade, * Significativo a 5\% de probabilidade. SB $=$ Substrato. Fonte: Dados dos Autores (2016). ${ }^{n s}$ not significant a 5\% at 5\% probability, ** Significant at $1 \%$ probability, * Significant at 5\% probability. SB $=$ Substrate. Source: Data from Authors (2016).

Com relação ao enraizamento os resultados demonstraram que houve diferença estatística entre os diferentes substratos testados, sendo: o substrato orgânico comercial (SOC) e a mistura de substrato orgânico com terra $(\mathrm{SOC}+\mathrm{TB})$ significativamente diferentes quando comparados à terra de barranco (TB), caracterizando dessa forma que os dois substratos não diferiram entre si (Tabela 2).

Tabela 2. Enraizamento (E), número de raízes (NR) e comprimento médio de raízes (CMR) em estacas de astrapéia (Dombeya wallichii). Dois Vizinhos, PR, UTFPR, 2016. Rooting (E), roots numbers (NR), mean root length (CMR), on stakes of astrapéia (Dombeya wallichii). Dois Vizinhos, PR, UTFPR, 2016.

\begin{tabular}{clll}
\hline Substrato & E $(\%)$ & NR & CMR $(\mathrm{cm})$ \\
\hline SOC. & $60,0 \mathrm{a}$ & $5,37 \mathrm{a}$ & $6,53 \mathrm{a}$ \\
TB. & $32,5 \mathrm{~b}$ & $3,21 \mathrm{~b}$ & $4,74 \mathrm{a}$ \\
SOC. + TB. & $75,0 \mathrm{a}$ & $4,46 \mathrm{ab}$ & $6,25 \mathrm{a}$ \\
\hline MÉDIA & 55,8 & 4,34 & 5,84 \\
\hline CV\% & 20,46 & 21,37 & 33,60 \\
DMS & 22,58 & 1,87 & 3,88 \\
\hline
\end{tabular}

SOC = Substrato Orgânico Comercial; TB = Terra de barranco; SOC + TB = Mistura de Substrato Orgânico Comercial com terra de barranco. *As médias seguidas pela mesma letra minúscula na coluna, não diferem estatisticamente entre si pelo Teste de Tukey a 5\% de probabilidade. Fonte: Dados de Autores (2016). SOC = Commercial Organic Substrate; $T B=$ embankment land; $S O C+T B=$ Mixture of Commercial Organic Substrate with ravine Earth. *Means followed by the same lowercase letter in the column do not differ statistically from each other by the Tukey test at $5 \%$ probability. Source: Data from Authors (2016).

Os melhores resultados para o enraizamento (E) foram observados na mistura entre os substratos SOC + TB (75 \%) e em SOC (60\%) (Tabela 2). Assim sendo, constatou-se que o uso de substrato orgânico puro ou em mistura com terra de barranco proporcionou sucesso no enraizamento, sendo uma opção para produção de mudas da espécie. Já o menor valor obtido 
foi verificado no substrato TB (32,5\%), demonstrando-se significativamente inferior aos demais substratos.

Masiero et al. (2016) ao avaliar tipos de estacas e substratos na propagação de astrapéia (Dombeya wallichii), obtiveram a maior porcentagem de enraizamento (45\%) em estacas com meia folha em substrato orgânico comercial Mecplant ${ }^{\circledR}$. Apesar dos resultados serem menores do que no presente trabalho, recomendaram para a produção de mudas da espécie o referido substrato.

Por meio dos resultados evidenciou-se que o SOC é uma excelente opção na produção de mudas, visto que o mesmo apresenta propriedades que desempenham sucesso para o enraizamento das estacas, de tal modo, tais características são importantes devido ao fato de estarem ligadas aos atributos necessários para produção de mudas de qualidade (PAULUS et al., 2011). Sendo assim, para aprimorar as propriedades físicas, químicas e biológicas dos substratos são utilizados componentes orgânicos, com finalidade de contribuir e melhorar as qualidades do substrato para a produção de mudas (DELARMELINA et al., 2014).

Outros trabalhos utilizando substratos orgânicos demostraram que, apesar das diferentes marcas existentes no mercado, esse substrato mostra-se eficiente por apresentar características importantes e desejáveis para as mudas, entre elas a retenção de água se destaca. Segundo Barbosa et al. (2018), em estudos sobre a caracterização de atributos físicos de substratos para fins de produção de mudas, identificaram que o SOC, possui alta porosidade total associada à baixa densidade caracterizando-o como um substrato de maior retenção de água.

Dessa maneira, estudos referentes ao substrato adequado demonstram que o mesmo deve ser poroso, permitindo que haja trocas gasosas para disponibilização de oxigênio na base das estacas, concedendo maior atividade celular durante a formação de calos para posterior emissão das raízes, reforçando assim que o substrato é um fator de grande influência na produção de mudas (SOUSA et al., 2005; GOMES et al., 2015). O melhor substrato deverá ser estabelecido, quando sua utilização no enraizamento e ou desenvolvimento da cultura forem comprovados como eficientes (BARBOSA et al., 2018).

No entanto, como caracterizado no presente estudo a mistura de dois materiais favorece o enraizamento de estacas, pois permite atingir níveis intermediários de retenção de água, de aeração e de disponibilidade de água nos substratos (SOUZA et al., 2006). Verifica-se assim a necessidade de fazer a mistura de componentes e selecionar a melhor combinação para encontrar o substrato que atenda as características físicas e nutricionais exigidas pelas mudas (PAULUS et al., 2011). Masiero et al. (2016) em seu estudo, além de recomendar o uso de SOC, evidenciou e sugeriu que para propagação de astrapéia seja utilizada a mistura de SOC $+\mathrm{TB}$.

Entretanto, apesar dos resultados favorecerem o uso do substrato terra de barranco em mistura com substrato orgânico comercial, evidencia-se que a terra de barranco é um substrato que apresenta um grau de risco de contaminação de nematóides não se caracterizando como substrato mais adequado para a propagação, considerando os requisitos fitossanitários previstos na Instrução Normativa ${ }^{\circ} 19$ de 22 de junho de 2018 (BRASIL, 2018). Assim sendo, o referido substrato vem sendo utilizado até então como rotina para reduzir custos por 
agregar volume no preparo, e nesse caso em específico, a utilização do mesmo visou buscar avaliar a eficiência no enraizamento de estacas.

O baixo enraizamento registrado em TB, pode ser justificado pela alta densidade desse substrato assim como sua baixa porosidade e retenção de água, porém uma das principais vantagens desse substrato é seu baixo custo, sendo uma boa opção para o viveirista. Uma alternativa que vem gerando bons resultados, como apresentada no presente estudo é a mistura com outros substratos, condicionando e viabilizando sua utilização (GOMES et al., 2015). Arruda et al. (2007) estudando o enraizamento de estacas herbáceas de guaranazeiro em diferentes substratos, concluíram que a mistura de substratos é essencial para o sucesso do enraizamento, sendo que para esse estudo o substrato comercial e o esterco de galinha + carvão proporcionaram maior porcentagem de enraizamento, com 55,9\% e 49,3\%, respectivamente.

Outro fator importante a ser avaliado no estudo é que as estacas foram oriundas de brotações, as quais possuem maior juvenilidade auxiliando no enraizamento. Estacas herbáceas e semilenhosas geralmente enraízam com maior facilidade e rapidez que as lenhosas, pois nelas há menor lignificação dos tecidos, facilitando consequentemente a passagem das raízes formadas no periciclo (BROWSE, 1979; TAIZ et al., 2017; HARTMANN et al., 2018). Nesse aspecto com relação aos tecidos de lignificação das estacas estão também a absorção de água e disponibilidade de nutrientes (PICOLOTTO et al., 2015).

Zem et al. (2015) estudando estaquia caulinar herbácea e semilenhosa de cataia (Drimys brasiliensis), encontraram em estacas herbáceas enraizamento de 46,75\% teoricamente, melhor do que em estacas semilenhosas (34,44\%). Já Sousa et al. (2013), obtiveram respostas similares ao presente trabalho em experimento realizado com estacas herbáceas e lenhosas de figueira (Ficus carica L.), sendo o melhor enraizamento obtido em estacas herbáceas $(68,3 \%)$.

Para variável número de raízes (NR) (Tabela 2), o SOC apresentou o maior média entre os substratos $(5,37)$, diferindo estatisticamente da TB $(3,41)$. Já a mistura SOC + TB $(4,46)$, poderia ser caracterizada como uma segunda opção de escolha, por não diferir estatisticamente dos demais substratos.

De fato, o NR é dependente de que os substratos apresentem estruturas físicas favoráveis, sendo que a porosidade e retenção de água são consideradas como as principais, visto que influenciam na emissão inicial das raízes, fundamentais na etapa de propagação (YAMAMOTO et al., 2012). Alguns substratos como a terra de barranco possuem alta densidade e pouca porosidade, não sendo características desejáveis para o enraizamento de estacas, exceto quando misturados com outros componentes (KÄMPF, 2000).

O comprimento médio de raízes (CMR) (Tabela 2) não apresentou diferença significativa entre os substratos, porém a maior média apresentada foi de 6,53 , obtido no substrato SOC. Com relação a essa variável, a menor média obtida na TB pode estar ligada ao déficit hídrico que o substrato possui, pela baixa retenção de água. A deficiência hídrica afeta a taxa fotossintética, contudo, também pode provocar redução das divisões celulares dos tecidos meristemáticos da planta, ocasionando crescimento proporcionalmente menor (ARAUJO; CASTRO NETO, 2002). 
A disponibilidade de água influencia diretamente no desempenho do comprimento radicial das estacas (FACHINELLO et al., 2005). De acordo com KÄMPF et al. (2006), os valores mais elevados de densidade podem representar maior resistência à expansão das raízes no substrato.

Yamamoto et al. (2012) estudando substratos no enraizamento de estacas herbáceas de amora-preta Xavante (Rubus spp.), relataram que quanto mais denso o substrato maior é a dificuldade do crescimento radicial. Já Pacheco e Franco (2008), estudando substratos e estacas no enraizamento de açoita-cavalo (Luehea divaricata), descreveram valores próximos aos encontrados no presente trabalho, porém, na ocasião os maiores valores encontrados para comprimento radicial foram obtidos em turfa $(5,10 \mathrm{~cm})$ e Plantmax ${ }^{\circledR}(4,57 \mathrm{~cm})$. Contudo, o substrato Mecplant ${ }^{\circledR}$ apresentou a disponibilidade de água abaixo dos valores recomendados para essa espécie, restringindo o crescimento radicial em L. divaricata. Assim, é de suma importância a escolha do substrato visto que pode variar de acordo com a espécie utilizada em questão.

Quanto à taxa de mortalidade $(\mathrm{M})$, observou-se que na $\mathrm{TB}$ verificou-se a maior média (60\%), sendo assim esse substrato foi estatisticamente superior aos demais (Tabela 3). A TB obteve resultados considerados inapropriados para a propagação vegetativa da $D$. wallichii, uma vez que apresentou mortalidade superior à $50 \%$.

Tabela 3. Mortalidade (M), Sobrevivência (S), porcentagem de calosidade (C) e porcentagem de brotações (B) em estacas de astrapéia (Dombeya wallichii). Dois Vizinhos, PR, UTFPR, 2016. Survival (S), mortility (M), porcentage of callosity (C) Sprout porcentage (B) on stakes of astrapéia (Dombeya wallichii) on stakes of astrapéia (Dombeya wallichii). Dois Vizinhos, PR, UTFPR, 2016.

\begin{tabular}{ccccc}
\hline \multirow{2}{*}{ Substrato } & $\mathrm{M}$ & $\mathrm{S}$ & $\mathrm{C}$ & $\mathrm{B}$ \\
\cline { 2 - 5 } SOC. & $35,0 \mathrm{~b}$ & $5,0 \mathrm{a}$ & $0,0 \mathrm{a}$ & $60,0 \mathrm{a}$ \\
TB. & $60,0 \mathrm{a}$ & $5,0 \mathrm{a}$ & $2,5 \mathrm{a}$ & $12,5 \mathrm{~b}$ \\
SOC. + TB. & $10,0 \mathrm{c}$ & $7,5 \mathrm{a}$ & $7,5 \mathrm{a}$ & $50,0 \mathrm{a}$ \\
\hline MÉDIA & 35,0 & 5,83 & 3,33 & 40,83 \\
\hline CV\% & 31,5 & 122,2 & 122,4 & 35,5 \\
DMS & 21,84 & 17,11 & 8,06 & 28,52
\end{tabular}

$\%=$ Porcentagem; SOC $=$ Substrato Orgânico Comercial; $\mathrm{TB}=$ Terra de barranco; $\mathrm{SOC}+\mathrm{TB}=$ Mistura de Substrato Orgânico Comercial com terra de barranco. *As médias seguidas pela mesma letra minúscula na coluna, não diferem estatisticamente entre si pelo Teste de Tukey a 5\% de probabilidade. Fonte: Dados de Autores (2016). \% = Percentage; SOC = Commercial Organic Substrate; $T B=$ embankment land; $S O C+T B=$ Mixture of Commercial Organic Substrate with ravine Earth. *Means followed by the same lowercase letter in the column do not differ statistically from each other by the Tukey test at 5\% probability. Source: Data from Authors (2016).

Os resultados de mortalidade verificados no presente trabalho assemelham-se aos obtidos por Masiero et al. (2016), que também se apresentaram superiores a $50 \%$ de mortalidade. Braga et al. (2006) apontaram a alta taxa de mortalidade das estacas de $P$. actinia e P. setace como o principal fator limitante ao enraizamento. A mortalidade assim como as demais variáveis (E, CMR e NR) são ligadas ao balanço hídrico do substrato, visto 
que substratos com baixa retenção de água, tornam-se mais densos e menos aerados, ocasionando aumento a mortalidade (BONFIM et al., 2011).

Com relação a porcentagem de sobrevivência $(S)$ e calosidade $(C)$ não houve diferença estatística entre os substratos (Tabela 3). Para a taxa de sobrevivência constatou-se que os substratos tiveram médias de 5,0 a 7,5\%, já para a calosidade verificou-se porcentagens de 0,0 a 7,5\%. Para essas variáveis ressalta-se que os baixos valores estão relacionados às elevadas taxas de enraizamento obtidos em SOC e na mistura SOC + TB, assim como à alta mortalidade obtida no TB. Quando o enraizamento atinge valores elevados o desempenho foi significativo, com isso outras variáveis acabam não se destacando. A sobrevivência e porcentagem de calos se demonstraram pouco significativas no trabalho.

A porcentagem de brotações (B) (Tabela 3), se manteve maior nos substratos SOC e SOC + TB com valores variando entre 50 a $60 \%$ de brotações, apresentando diferença estatística quando comparados a TB, que obteve apenas $12,5 \%$ de brotações. $\mathrm{O}$ desenvolvimento de brotações nas estacas teve um comportamento semelhante ao enraizamento, no qual a análise estatística mostrou significância em função do substrato utilizado.

Crispim et al. (2015) estudando estaquia de Pyrostegia venusta, constatou que a quantidade de brotações nas estacas foi influenciada pelo tipo de substrato, sendo que na ocasião o substrato foi a mistura de areia lavada + Plantmax ${ }^{\circledR}$, havendo aumento de brotações, acarretando em melhor desenvolvimento da muda, visto que proporcionou aumento de área foliar, consequentemente maiores taxas fotossintéticas. Dessa maneira os nutrientes minerais ou componentes presentes no substrato influenciam no sucesso das brotações, pois fornecem minerais que atuam como ativadores do processo fotossintético (TAIZ et al., 2017).

De maneira geral o substrato influenciou diretamente no sucesso do enraizamento e, consequentemente, na qualidade da muda. Contudo, as várias alternativas de substrato existentes no mercado favorecem a escolha, pois cada um possui características físicas e químicas próprias e desejáveis, sendo importante também o conhecimento das características das espécies para que desenvolvam um sistema radicial melhor formado no substrato escolhido. Dessa maneira a utilização de SOC favoreceu, além da retenção de água, a nutrição da muda, fornecendo condições adequadas para seu desenvolvimento.

\section{CONCLUSÃO}

Para a produção de mudas de Dombeya wallichii a partir de estacas provenientes de brotações da base da planta matriz recomenda-se a utilização de substrato orgânico comercial e da mistura de substrato orgânico comercial e terra de barranco.

Entretanto, ressalta-se que a utilização de terra de barranco não é recomendada para a produção comercial de mudas, devido ao risco de contaminação por nematóides presentes nesse substrato. 


\section{REFERÊNCIAS BIBLIOGRÁFICAS}

ALVARES, C. A.; STAPE, J. L.; SENTElHAS, P. C; GONÇALVES, J. L. M.; SPAROVEK, G. Köppen's climate classification map for Brazil. Meteorologische Zeitschrift, Stuttgart, Alemanha, v. 22, n. 6, p.711-728, 2013.

AMARO, H. T. R; SILVEIRA, J. R; DAVID, A. M. S de S; RESENDE, M. A. V de; ANDRADE, J. A. S. Tipos de estacas e substratos na propagação vegetativa da menta (Mentha arvensis L.). Revista Brasileira Plantas Medicinais, Campinas, v. 15, n. 3, p.313318 , 2013.

Disponível

em: http://www.conhecer.org.br/enciclop/2011b/ciencias\%20agrarias/influencia\%20de\%20diferen tes.pdf. Acesso em: 03 mai. 2018.

ARAÚJO, F. P.; CASTRO NETO, M. T. Influência de fatores fisiológicos de plantasmatrizes e de épocas do ano no pagamento de diferentes métodos de enxertia do umbuzeiro. Revista Brasileira de Fruticultura, Jaboticabal, v. 24, n. 3, p. 752-755, 2002. Disponível em: http://www.scielo.br/pdf/rbf/v24n3/15132.pdf. Acesso em: 08 jun. 2018.

ARRUDA, M. R.; PEREIRA, J. C. R.; MOREIRA, A.; TEIXEIRA, W. G. Enraizamento de estacas herbáceas de guaranazeiro em diferentes substratos. Revista Ciência agrotécnica, Lavras, $\quad$ v. $31, \quad$ n. 1 , p.236-241, 2007. Disponível em: http://www.scielo.br/pdf/cagro/v31n1/v31n1a35.pdf. Acesso em: 03 Jun. 2018.

BARBOSA, J. R. L.; RIGON, F.; CONTE, A. M.; SATO, O. Caracterização de atributos físicos de substratos para fins de produção de mudas. Revista Cultivando o Saber, Cascavel, v. $11, \quad$ n. $1, \quad$ p.13-25, 2018. Disponível em: https://www.fag.edu.br/upload/revista/cultivando_o_saber/5ab39af2b5694.pdf. Acesso em: 02 mai. 2018.

BONFIM, F. P. G.; CASALI, V. W. D.; VALADARES, L. M.; FREITAS, J. da. S.; MARQUES, G. R. Influência de diferentes tipos de estacas e substratos na propagação assexuada de cavalinha (Equisetum arvense L.). Revista Enciclopédia Biosfera, Goiânia, v. 7, n. 13, p.694-700, 2011. Disponível em: http://www.conhecer.org.br/enciclop/2011b/ciencias\%20agrarias/influencia\%20de\%20diferen tes.pdf. Acesso em: 01 mai. 2018.

BORGES, S. R.; XAVIER, A.; L. S.; MELO, L. A.; ROSADO, A. M. Enraizamento de miniestacas de clones híbridos de Eucalyptus globulus. Revista Árvore, Viçosa, v. 35, n. 3, p.425-434, 2011. Disponível em: http://www.scielo.br/pdf/rarv/v35n3/a06v35n3.pdf. Acesso em: 15 mai. 2018.

BRAGA, M. F.; SANTOS, E. C.; JUNQUEIRA, N. T. V.; SOUSA, A. A. T. C.; FALEIRO, F. G.; REZENDE, L. N.; JUNQUEIRA, K. P. Enraizamento de estacas de três espécies silvestres de passiflora. Revista Brasileira Fruticultura, Jaboticabal, v. 28, n. 2, p.284-288, 2006. Disponível em: http://www.scielo.br/pdf/rbf/v28n2/a29v28n2. Acesso em: 29 mai. 2018.

BRASIL. Ministério da Agricultura, Pecuária e Abastecimento. Instrução Normativa $\mathrm{n}^{\circ}$ 19, de 22 de junho de 2018. Diário Oficial [da] República Federativa do Brasil, Brasília, 04 de 
julho de 2018. Disponível em: http://www.in.gov.br/materia//asset_publisher/Kujrw0TZC2Mb/content/id/28503222/do1-2018-07-04-instrucao-normativan-19-de-22-de-junho-de-2018-28503190. Acesso em: 23 jul. 2019.

BROWSE, P. M. A Propagação das plantas: sementes, raízes; bulbos e rizomas, mergulhia, estacas de madeira e foliares, enxertia de borbulha e de cavalo e garfo. Lisboa: EuropaAmérica, 1979. 228 p.

CRISPIM, J. G.; RÊGO, M. M.; RÊGO, E. R.; PESSOA, A. M. S.; BARROSA, P. A. Utilização de diferentes substratos na propagação de Pyrostegia venusta através de estacas. Revista Verde de Agroecologia e desenvolvimento sustentável, Pombal, v. 10, n. 4, p.3841, 2015. Disponível em: https://www.gvaa.com.br/revista/index.php/RVADS. Acesso em: 28 mai. 2018.

DIAS, P. C.; OLIVEIRA, L. S.; XAVIER, A. E.; WENDLING, I. Estaquia e miniestaquia de espécies florestas lenhosas do Brasil. Pesquisa Florestal Brasileira, Colombo, v. 32, n. 72, p.453-454, 2012. Disponível em: https://pfb.cnpf.embrapa.br/pfb/index.php/pfb/article/view/388/289. Acesso em: 05 mai. 2018.

DELARMELINA, W. M.; CALDEIRA, M. V. W.; FARIA, J. C. T.; GONÇALVES, E. O.; ROCHA, R. L. F. Diferentes Substratos para a Produção de Mudas de Sesbania virgata. Revista Floresta e Meio ambiente, Rio de Janeiro, v. 21, n. 2, p.224-234, 2014. Disponível em:

http://www.scielo.br/scielo.php?pid=S217980872014000200010\&script=sci_abstract\&tlng=p t.pdf. Acesso em: 05 mai. 2018.

ESPINDOLA, A. E.; ORENHA, C. E. Flora Apícola em Santa Catarina: I - Astrapéia. Informativo Zum-Zum, Florianópolis, v. 41, n. 330, p.3, 2007.

FERREIRA, D. F. SISVAR: a computer statistical analysis system. Revista Ciência e Agrotecnologia, Lavras, v. 35, n. 6, p.1039-1042, 2011. Disponível em: http://www.scielo.br/pdf/cagro/v35n6/a01v35n6.pdf. Acesso em: 03 mai. 2018.

FIGUEIRÓ, P. R. P.; SILVA, C. R. C.; CASTO, A.; SHUNEMANN, A. P. R. Astrapéia Rosa: contribuição na produção de mel e condição dos enxames. Informativo Zum-Zum, Florianópolis, v. 44, n. 334, p.22, 2010. Disponível em: https://www.apacame.org.br/mensagemdoce/110/artigo2.htm. Acesso em: 05 mai. 2018.

FACHINELlO, J. C.; HOFFMANN, A.; NACHTIGAL, J. C. Propagação de plantas frutíferas. Brasília, DF: Embrapa Informação Tecnológica, 2005. 221 p.

GAULAND, D. C. S. P. Relações hídricas em substratos à base de turfas sob o uso dos condicionadores casca de arroz carbonizada ou queimada. 1997. 107 f. Dissertação (Mestrado em Ciência do Solo) - Universidade Federal do Rio Grande do Sul, Porto Alegre, 1997.

GONÇALVES, E. O; PAIVA, H. N; GONÇALVES W.; JACOVINE, L. A. G. Diagnóstico dos viveiros municipais no estado de minas gerais. Revista Ciência Florestal, Santa Maria, 
v. 14, n. 2, p.1-12, 2004. Disponível em: http://coral.ufsm.br/cienciaflorestal/artigos/v14n2/A1V14N2.pdf. Acesso em: 15 mar. 2018.

GOMES, L. A. A.; RODRIGUES, A. C.; COLliER, L. S.; FEITOSA, S. dos S. Produção de mudas de alface em substrato alternativo com adubação. Revista Horticultura Brasileira, Brasília, v. 26, n. 3, p.359-363, 2008. Disponível em: http://www.scielo.br/pdf/hb/v26n3/13.pdf. Acesso em: 18 abr. 2018.

GOMES, J. A. O.; TEIXEIRA, D. A.; MARQUES, A. P. S.; BONFIM, F. P. G. Diferentes substratos na propagação por estaquia de assa-peixe (Vernonia polyanthes Less). Revista Brasileira Plantas Medicinais, Campinas, v. 17, n. 4, p.1159-1168, 2015. Disponível em: http://www.scielo.br/pdf/rbpm/v17n4s3/1516-0572-rbpm-17-4-s3-1177.pdf. Acesso em: 15 abr. 2018.

HARTMANN, H. T.; KESTER, D. E.; DAVIES JÚNIOR, F. T.; GENEVE, R. L. WILSON, S. B. Plant propagation: principles and practices. 9 ed. New Jersey: Prentice Hall, 2018. $1024 \mathrm{p}$.

KÄMPF, A. N. Produção comercial de plantas ornamentais. Guaíba: Agropecuária. 2000. $254 \mathrm{p}$.

KÄMPF, A. N.; TAKANE, R. J.; SIQUEIRA, P. T. V. Floricultura: técnicas de preparo de substratos. Brasília, DF: LK, 2006. 132 p.

LORENZI, H.; BACHER, L. B.; TORRES, M. A. V. Árvores e arvoretas exóticas no Brasil: madeireiras, ornamentais e aromáticas. Nova Odessa: Plantarum, 2018. 464 p.

MASIERO, M. A.; MINOZZO, M.; WEIS, E. C.; FALICETI, M. L.; DE LIMA, D. M. Influência de tipos de estaca e substrato na produção de mudas de astrapéia (Dombeya wallichii) como espécie alternativa ao desenvolvimento na apicultura na região sudoeste do Paraná. In: SEMINÁRIO DE EXTENSÃO E INOVAÇÃO DA UTFPR, 6., 2016, Francisco Beltrão. Anais [....] Francisco Beltrão: Universidade Tecnológica Federal do Paraná - SEIUTFPR, 2016. p.01-12.

PACHECO, J. P.; FRANCO, E. T. H. Substratos e estacas com e sem folhas no enraizamento de Luehea divaricata Mart. Ciência Rural, Santa Maria, v. 38, n. 7, p.1900-1906, 2008. Disponível em: http://www.scielo.br/pdf/cr/v38n7/a15v38n7.pdf. Acesso em: 03 mai. 2018.

PAUlinO, R. C.; HENRIQUES, G. P. S. A.; COELHO, M. F. B.; DOMBROSKI, J. D. Diferentes substratos na propagação por estaquia de Cordia globosa e Cordia leucocephala. Revista Verde, Mossoró, v. 6, n. 4, p.274-278, 2011. Disponível em: http://www.gvaa.com.br/revista/index.php/RVADS/article/viewFile/1092/959. Acesso em: 03 mai. 2018.

PAUlUS, D.; VALMORBIDA, R.; TOFFOLI, E.; PAUlUS, E.; GARLET, T. M. B. Avaliação de substratos orgânicos na produção de mudas de hortelã (Mentha gracilis $\mathrm{R}$. Br. e Mentha x villosa Huds.). Revista Brasileira Plantas Medicinais, Paulínia, v. 13, n. 1, p.9097, 2011. Disponível em: http://www.scielo.br/pdf/rbpm/v13n1/v13n1a14.pdf. Acesso em: 03 mai. 2018. 
PICOLOTTO, L.; VIGNOLO, G. K.; PEREIRA, I. S.; GONÇALVES, M. A.; ANTUNES, L. E. C. Enraizamento de estacas de amoreira-preta em função da adubação nitrogenada na planta matriz. Revista Ceres, Viçosa, v. 62, n. 3, p.294-300, 2015. Disponível em: http://www.scielo.br/pdf/rceres/v62n3/0034-737X-rceres-62-03-00294.pdf. Acesso em: 11 jun. 2018.

SOUZA, P. V. D.; CARNIEL, E.; FOCHESATO, M. L. Efeito da composição do substrato no enraizamento de estacas de maracujazeiro azedo. Revista Brasileira Fruticultura, Jaboticabal, v. 28 , n. 2, p.276-279, 2006. Disponível em: https://www.lume.ufrgs.br/bitstream/handle/10183/20215/000550870.pdf?sequence=1. Acesso em: 08 mai. 2018.

SOUSA, P. B. L.; AYALA-OSUNA, J. T.; GOMES, J. E. Propagação vegetativa de Ocimum gratissimum L. em diferentes substratos. Revista Brasileira Plantas Medicinais, Botucatu, v. $8, \quad$ n. $1, \quad$ p.39-44, 2005. Disponível em: http://www.sbpmed.org.br/download/issn_05_4/artigo9_v8_n1.pdf. Acesso em: 03 mai. 2018. SOUSA, C. M.; BUSQUET, R. N.; VASCONCELLOS, M. A. S.; MIRANDA, R. M. Effects of auxin and misting on the rooting of herbaceous and hardwood cuttings from the fig tree. Revista Ciência Agronômica, Fortaleza, v. 44, n. 2, p.334-338, 2013. Disponível em: http://www.scielo.br/scielo.php?script=sci_arttext\&pid=S1806-66902013000200016. Acesso em: 11 jun. 2018.

TAIZ, L.; ZEIGER, E.; MØLLER, I. A.; MURPHY, A. Fisiologia e desenvolvimento vegetal. 6. ed. Porto Alegre: Artmed, 2017. 858 p.

WENDLING, I. OAIVA, H. N.; GONÇALVES, W. Técnicas de produção de mudas de plantas ornamentais. Viçosa, MG: Aprenda Fácil, 2005. 223 p.

WENDLING, I.; DUTRA, L. F. (ed.). Produção de mudas de eucalipto. Colombo: Embrapa Florestas, 2010. 184 p.

YAMAMOTO, L. Y.; KOYAMA, R. BORGES, W. F. S.; ANTUNES, L. E. C.; ASSIS, A. M.; ROBERTO, S. R. Substratos no enraizamento de estacas herbáceas de amora-preta Xavante. Ciência Rural, Santa Maria, v. 43, n. 1, p.15-20, 2013. Disponível em: http://www.scielo.br/pdf/cr/v43n1/a1713cr2012-0499.pdf. Acesso: 06 mai. 2018.

ZEM, L. M.; WEISER, A. H.; RUFFELLATO-RIBAS, K. H.; RODOMSKI, M. I. Estaquia caulinar herbácea e semilenhosa de Drimys brasiliensis Centro de Ciências Agrárias Universidade Federal do Ceará, Fortaleza, CE. Revista Ciência Agronômica, Fortaleza, v. 46, n. 2, p.396-403, 2015. Disponível em: http://www.scielo.br/pdf/rca/v46n2/0045-6888-rca46-02-0396.pdf. Acesso: 06 mai. 2018.

ZIETEMANN; C.; ROBERTO, S. R. Efeito de diferentes substratos e épocas de coleta no enraizamento de estacas herbáceas de goiabeira, cvs. Paluma e Século XXI. Revista Brasileira de Fruticultura, Jaboticabal, v. 29, n. 1, p.31-36, 2007. Disponível em: http://www.scielo.br/pdf/rbf/v29n1/a09v29n1.pdf. Acesso: 10 mai. 2018. 